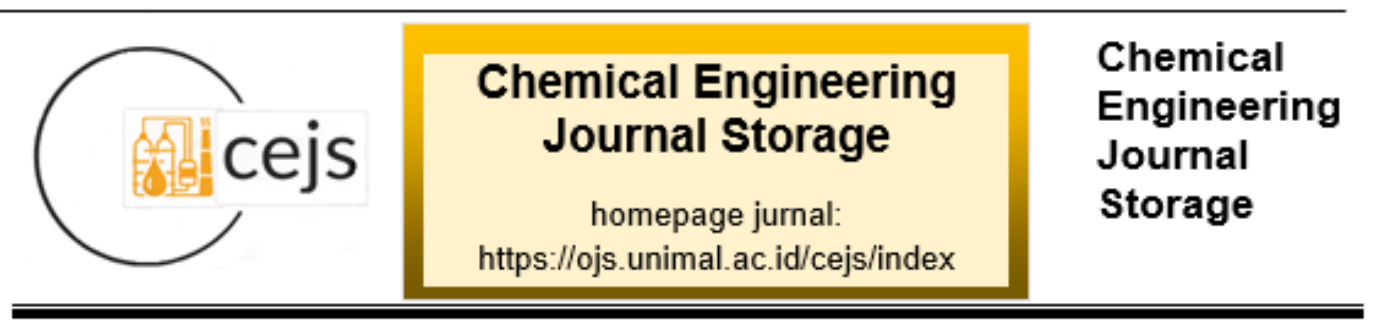

\title{
SIMULASI PENGARUH BUKAAN VALVE TERHADAP PRESSURE \\ DROP DAN KAVITASI PADA CONTROL VALVE TIPE BALL VALVE DENGAN MENGGUNAKAN SOFTWARE AUTODESK CFD (COMPUTATIONAL DYNAMICS FLUID)
}

\author{
Sindi Qistina Asriati', Nasrul ZA ${ }^{1}$, Muhammad ${ }^{1}$, Jalaluddin', Azhari ${ }^{1}$ \\ ${ }^{1}$ Jurusan Teknik Kimia, Fakultas Teknik, Universitas Malikussaleh \\ Kampus Utama Cot Teungku Nie Reuleut, Muara Batu, Aceh Utara - 24355 \\ Korespondensi:HP: 082164699680,e-mail: nasrulza@unimal.ac.id
}

\begin{abstract}
Abstrak
Control valve merupakan suatu instrumen yang digunakan dalam proses industri dan memiliki peran yang sangat penting. Sebagai final control element, control valve digunakan untuk mengatur aliran fluida agar mampu mengimbangi adanya gangguan serta tetap menjaga variable proses tetap berada pada set point yang diinginkan. Simulasi pengaruh bukaan valve terhadap pressure drop dan kavitasi pada control valve menggunakan autodeks CFD (2019). Kavitasi adalah suatu keadaan yang disebabkan oleh berubahnya fase cairan yang sedang dialirkan dari fase cair menjadi fase uap sehingga menimbulkan gelembung-gelembung. Timbulnya gelembung tersebut disebabkan oleh menurunnya tekanan hingga berada di bawah tekanan uap jenuh cairan tersebut. Adapun variable tetap yang digunakan adalah tekanan $4 \mathrm{~atm}, 5 \mathrm{~atm}, 6 \mathrm{~atm}$ dan bukaan valve $50 \%, 70 \%, 90$ $\%$ dan variable terikat Penurunan tekanan $(\Delta P)$, Bilangan reynold (NRe), Kavitasi (CN). Di dalam penggambaran geometri valve menggunakan autodeks fusion 360. Untuk bukaan valve yang kecil yaitu 50\% penurunan tekanannya sebesar 1.84 atm dengan tekanan awal 5 atm. Bilangan Reynold tertinggi pada bukaan valve 90\% dengan bilangan reynold 78,352 dan aliran yang terbentuk adalah turbulen. Indeks kavitasi terendah adalah sebesar 9.47 dan yang tertinggi 36.7. Pada percobaan ini dapat dilihat antara variable terikat, penurunan tekanan dan kavitasi serta variabel bebas bukaan valve dan tekanan yang paling berpengaruh.
\end{abstract}

Kata kunci: Autodesk Fusion 360, Autodesk Simulation CFD, Control Valve, Kavitasi.

\section{Pendahuluan}

Pada saat ini kemajuan teknologi dan industri sangat berkembang pesat, salah satunya ilmu teknik sangat berperan penting mendorong untuk mengaplikasikan ilmu tersebut dalam suatu masalah. Dalam sebuah industri, valve 
sangat berpengaruh terhadap berlangsungnya suatu proses, karena valve merupakan sebuah perangkat yang mengatur, mengarahkan atau mengontrol suatu aliran fluida dengan cara membuka, menutup atau menutup sebagian dari jalannya aliran. Pada suatu aliran fluida didalam valve sering terjadi adanya penurunan tekanan (pressure drop) dikarenakan beberapa faktor yaitu bukaan valve, koefisien torsi, koefisien kehilangan, koefisien aliran dan kekasaran permukan dinding valve. Penurunan tekanan pada valve perlu diketahui dikarenakan jika penurunan tekanan yang ditimbulkan pada valve semakin besar maka energi yang dibutuhan untuk mengalirkan fluida akan semakin besar sehingga dapat merugikan industriindustri (Flowserve, 2006).

Kavitasi adalah suatu keadaan yang disebabkan oleh berubahnya fase cairan yang sedang dialirkan dari fase cair menjadi fase uap sehingga menimbulkan gelembung-gelembung. Timbulnya gelembung tersebut disebabkan oleh menurunnya tekanan hingga berada di bawah tekanan uap jenuh cairan tersebut. Secara sederhana, kavitasi diartikan sebagai pembentukan gelembung uap dalam suatu aliran fluida akibat adanya pressure drop pada temperatur konstan. Apabila control valve bekerja dengan pressure drop yang relative tinggi, maka control valve tersebut dapat mengalami fenomena kavitasi ini (Agustiyan \& Bambang 2007).

Pada penelitian ini penulis memilih menganalisis kavitasi pada ball valve karena valve jenis ini banyak digunakan diindustri yakni seperti industri LPG/NPG, minyak kelapa sawit, minyak bumi, maupun gas. Hal ini dikarenakan valve ini sederhana, ringan, mudah diperbaiki dan harganya pun murah. Computational Dynamics Fluid (CFD) adalah suatu cabang mekanika fluida yang menggunakan metode numerik dan komputasi untuk memecahkan dan mengalisis masalah yang melibatkan dari aliran fluida tersebut. Untuk analisis ini komputer digunakan untuk melakukan perhitungan dan untuk mensimulasikan interaksi cairan ataupun gas dengan permukaan yng dikondisikan oleh kondisi batas, dengan kecepatan yang tinggi super komputer, agar mendapatkan analisis yang lebih baik (Celik et al., 2011). 


\section{Bahan dan Metode}

Penelitian ini bersifat komputasi numeric dimulai dengan penggambaran geometri Ball Valve dengan menggunakan software Autodesk Fusion 360 kemudian untuk kalkulasi numeriknya menggunakan software Autodesk Simulation CFD.

Tahap I

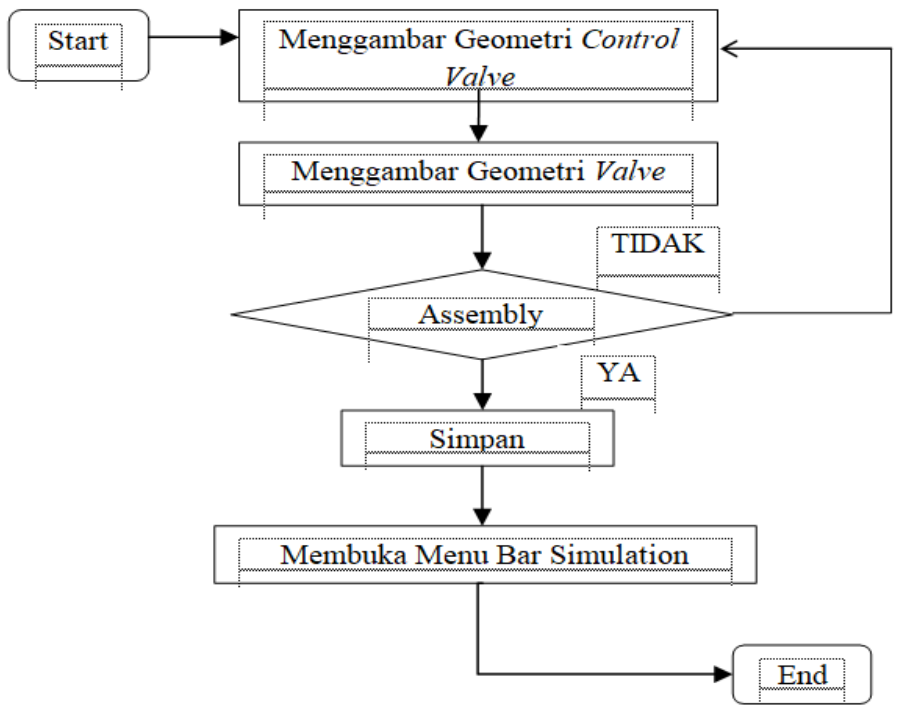

Gambar 1. Bagan Alir Prosedur Autodesk Fusion 360

Tahap II

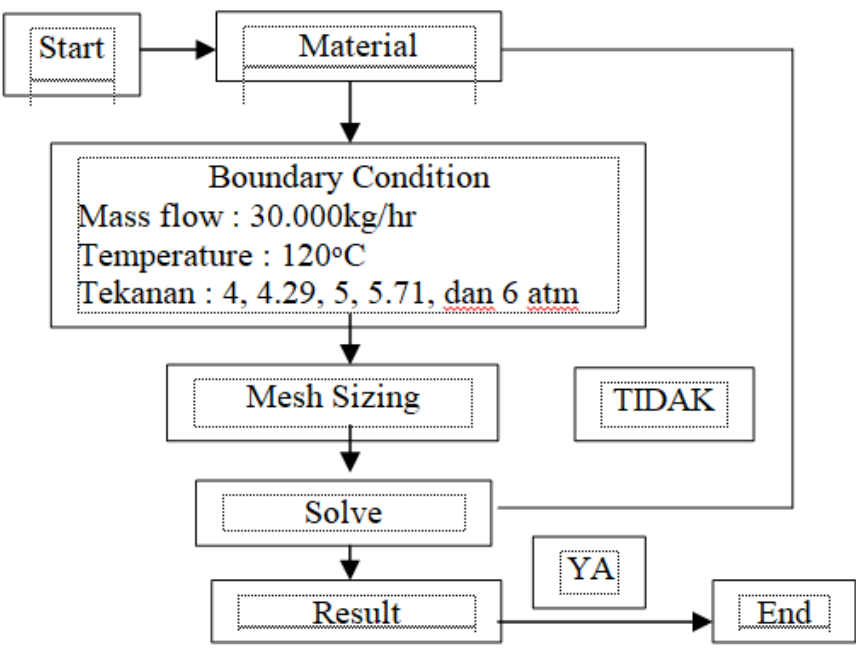

Gambar 2. Bagan Alir Prosedur CFD 


\section{Hasil dan Diskusi}

\subsection{Hasil}

Simulasi pengaruh pressure drop dan kavitasi tipe ball valve pada control valve dilakukan dengan menggunakan software autodesk CFD. Selanjutnya variabel tetap dan variabel bebas dimasukkan pada saat menginisial setup. Simulasi ball valve dilakukan sebanyak 9 kali dengan memakai rancangan Central Composite Design (CCD) secara acak dan hasil simulasi pengaruh pressure drop dan kavitasi dapat dilihat pada Tabel 3.1

\begin{tabular}{|c|c|c|c|c|c|}
\hline Run & $\begin{array}{c}\text { Bukaan } \\
\text { Valve } \\
(\%)\end{array}$ & $\begin{array}{c}\text { Tekanan } \\
(\mathrm{atm})\end{array}$ & Pressure Drop $(\Delta \mathrm{p})$ & Kavitasi & NRe \\
\hline 1 & 50 & 5 & 1.84 & 9.47 & 30,317 \\
\hline 2 & 55.86 & 4.29 & 1.87 & 15.58 & 32,974 \\
\hline 3 & 55.86 & 5.71 & 2.34 & 10.05 & 37,548 \\
\hline 4 & 70 & 4 & 1.74 & 21.65 & 41,665 \\
\hline 5 & 70 & 5 & 2.25 & 23.01 & 47,246 \\
\hline 6 & 70 & 6 & 4.36 & 36.7 & 51,288 \\
\hline 7 & 84.14 & 4.29 & 2.8 & 32.67 & 76,824 \\
\hline 8 & 84.14 & 5.71 & 3.58 & 34.92 & 77,143 \\
\hline 9 & 90 & 5 & 2.87 & 34.73 & 78,352 \\
\hline
\end{tabular}

Tabel 3.1 merupakan hasil penelitian dari simulasi pengaruh bukaan valve dan tekanan terhadap pressure drop dan kavitasi.

\subsection{Pengaruh Bukaan Valve dan tekanan terhadap Pressure Drop $(\Delta \mathbf{P})$}

Valve yang di design untuk mengatur aliran, disamping itu digunakan untuk menghentikan aliran fluida tetapi biasanya digunakan untuk mengatur aliran. Perubahan arah aliran fluida yang menembus valve menyebabkan kehilangan tekanan yang tinggi dan turbulensi atau gejolak. Variasi bukaan valve terhadap tekanan awal bertujuan untuk mengetahui besarnya kehilangan tekanan yang paling kecil. Pengaruh persen bukaan valve terhadap penurunan tekanan, dapat dilihat pada Gambar 3.1. 


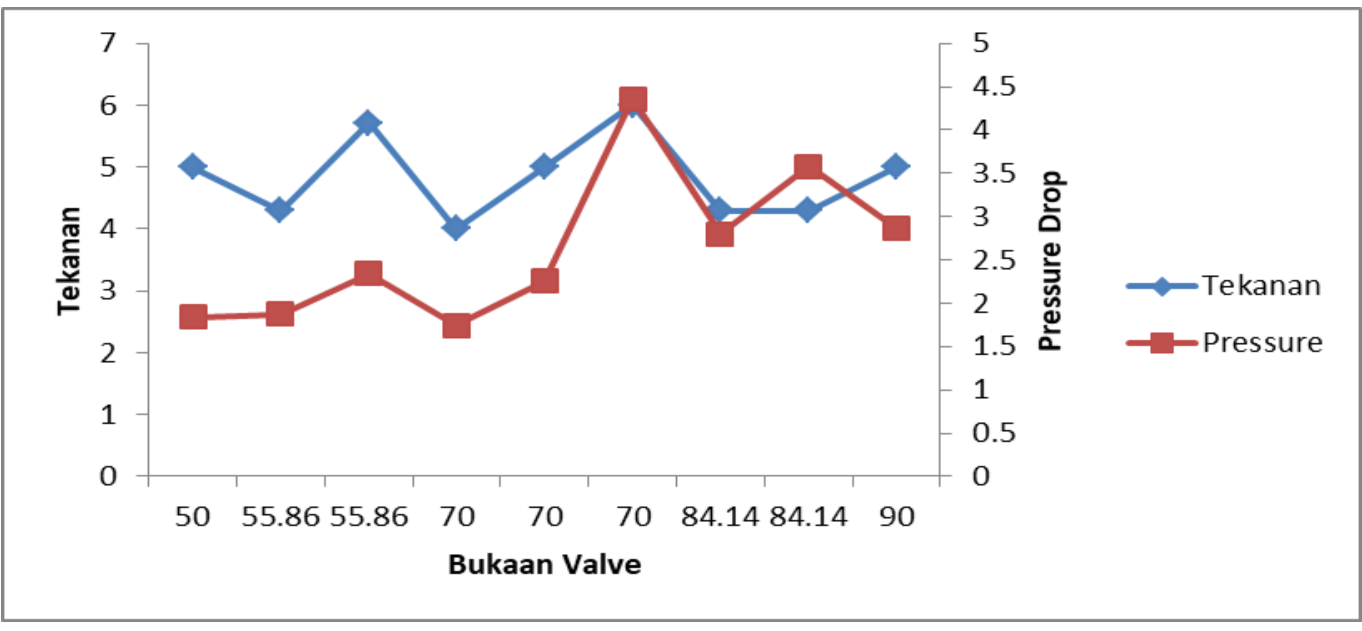

Gambar 3.1. Pengaruh Bukaan Valve dan tekanan terhadap Pressure Drop $(\Delta \mathrm{P})$

Gambar di atas menunjukkan pengaruh yang terjadi pada persentase bukaan valve, semakin besar persentase bukaan valve maka pressure drop yang dihasilkan semakin kecil begitu juga untuk laju alirannya. Hal ini disebabkan adanya perubahan pressure drop penurunan tekanan yang relatif tinggi pada saat temperaturnya tetap.

Dari gambar diatas juga menunjukkan pengaruh tekanan masuk terhadap pressure drop dimana semakin tinggi tekanan masuk yang diberikan maka pressure drop yang dihasilkan semakin besar pula hal ini disebabkan besarnya tekanan yang hilang disebabkan dengan fluida yang keluar dengan bukaan valve yang sama lebih besar dari pada tekanan masuk yang lebih kecil.

\subsection{Pengaruh bukaan valve dan tekanan terhadap bilangan Reynolds}

Angka Reynolds hanya berpengaruh pada besarnya vektor kecepatan aliran di sekitar katup. Pada semua perubahan sudut penutupan katup terdapat adanya pusaran. Pusaran terlihat pada dua lokasi, yaitu satu pusaran terjadi saat melintasi bodi disk katup dan lainnya terjadi di belakang disk katup (Hasbi, 2009).

Pada Gambar 3.2 menunjukkan hubungan Hubungan antara persentase bukaan valve dan tekanan terhadap Bilangan Reynolds dimana pressure drop pada bukaan ball valve menunjukkan peningkatan yang sama hal ini dipengaruhi oleh faktor gesekan pada aliran pipa yang lurus horizontal. 


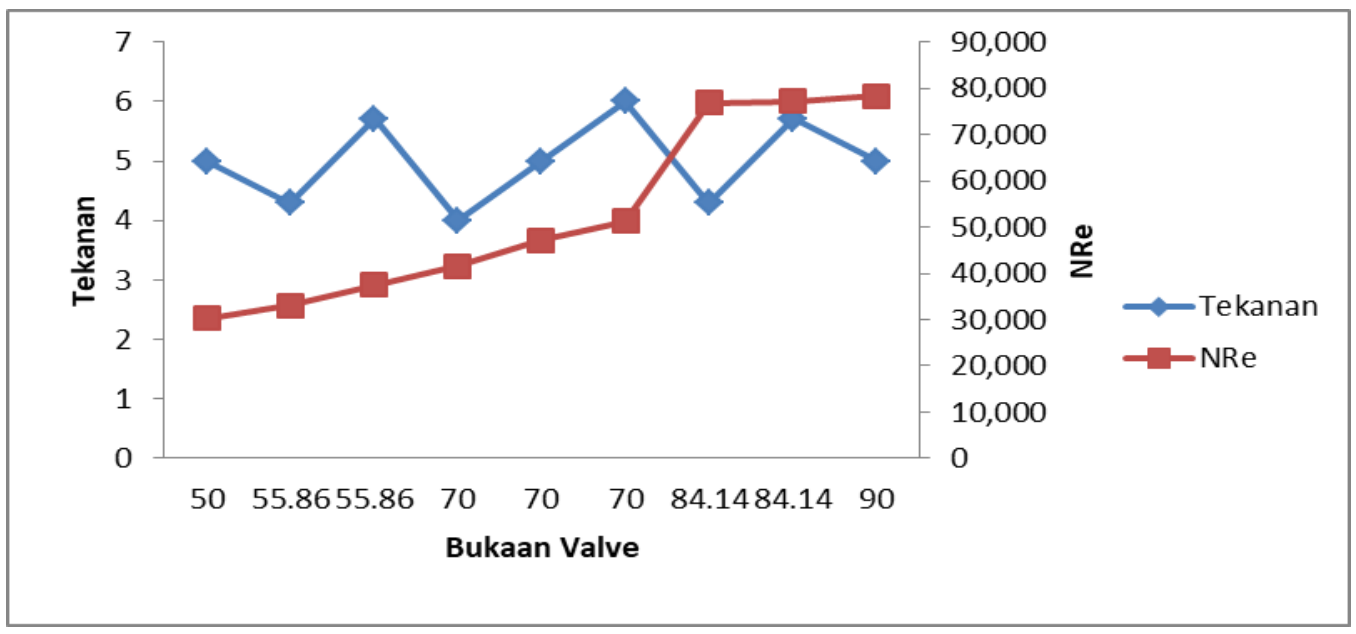

Gambar 3.2. Hubungan antara persentase bukaan valve dan tekanan terhadap

Bilangan Reynolds

Gambar 4.2 menunjukkan bahwa meningkatnya bilangan Reynolds untuk setiap variasi bukaan valve dan tekanan yang berbeda, hal ini terjadi karena peningkatan debit aliran yang disebabkan karena pengaruh besaran bukaan valve dan tekanan sehingga kecepatan alirannya semakin tinggi.

Dari variasi bukaan valve nilai bilangan reynold yang di dapat diatas 30.000 hal ini menyatakan bahwa aliran yang terbentuk turbulen, dan yang menyebabkan aliran keluaran bukaann valve turbulen dikarenakan pressure drop yang tinggi akibat geometri valve. Bilangan Reynolds sendiri dipengaruhi oleh kecepatan aliran fluida air, semakin besar bilangan Reynolds maka semakin tinggi kecepatan aliran air sehingga akan membuat pressure drop meningkat, akan menyebabkan aliran menjadi bergejolak dan bertubulensi atau disebut dengan aliran turbulen.

\subsection{Pengaruh Bukaan Valve dan Tekanan Terhadap Kavitasi}

Berdasarkan hasil simulasi tersebut dapat dilihat bahwa harga indeks kavitasi terendah adalah sebesar 9.47 dan yang tertinggi sebesar 36.7. Pengaruh bukaan valve terhadap kavitasi ditunjukkan pada Gambar 3.3. 


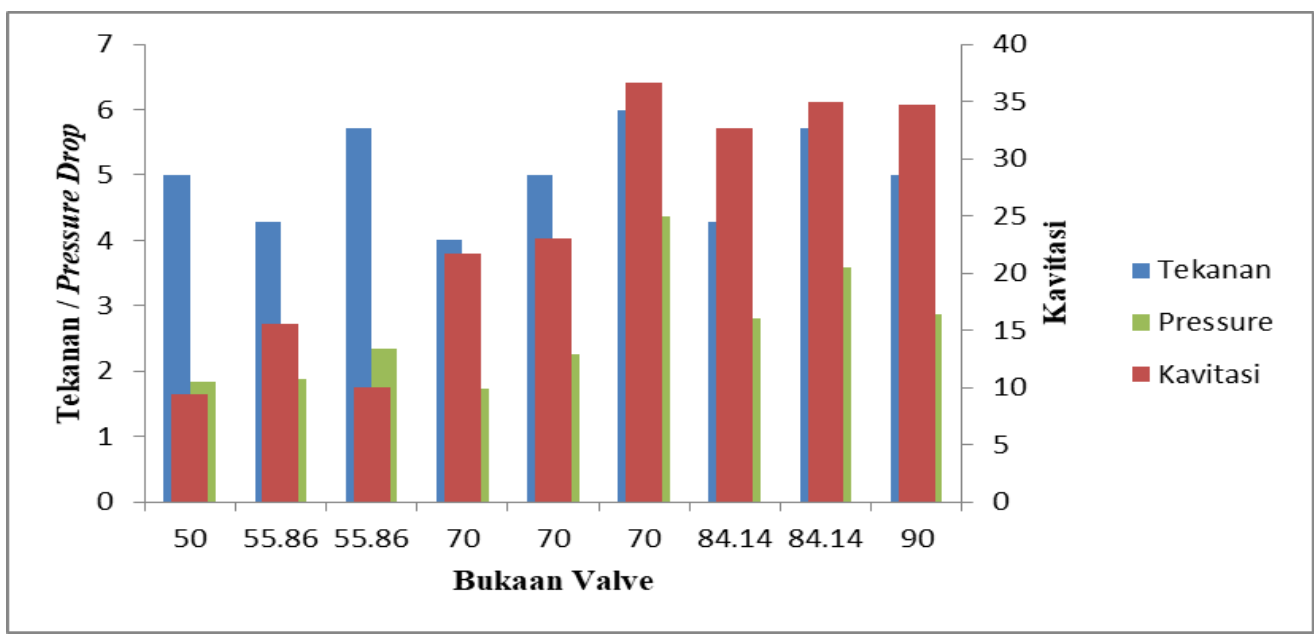

Gambar 3.4 Pengaruh Bukaan valve dan tekanan terhadap kavitasi

Gambar 3.4 menunjukkan pengaruh bukaan valve dan tekanan terhadap kavitasi. Pada bukaan valve sebesar $70 \%$ dengan tekanan 4 atm penurunan tekanan melebihi tekanan uapnya yaitu sebesar 1,74 atm dan nilai kavitasi yang diperoleh 21.65. Maka dari itu pada bukaan valve 70\% dengan tekanan 4 atm terdapat gravitasi pada Gambar 4.2 sedangkan pada tekanan yang berbeda pada bukaan valve $70 \%$ nilai kavitasi lebih besar yaitu 23.01 untuk tekanan $5 \mathrm{~atm}$ dan untuk tekanan 6 atm nilai kavitasi sebesar 36.7. Semakin tinggi pressure drop maka semakin besar kavitasi yang didapat hal ini terjadi pada valve bukaan $70 \%$ tekanan $6 \mathrm{~atm}$.

\subsection{Countor Distribusi Bukaan Valve dan Tekanan Terhadap Penurunan Tekanan dan Aliran Fluida}

Berikut merupakan counter distribusi bukaan valve dan tekanan terhadap penurunan tekanan aliran fluida adalah sebagai berikut.

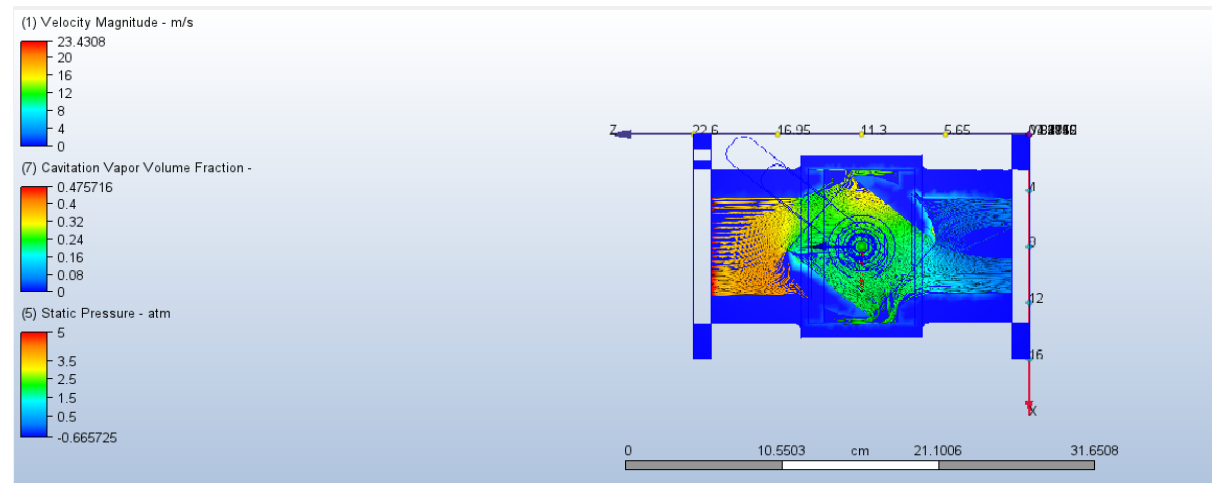




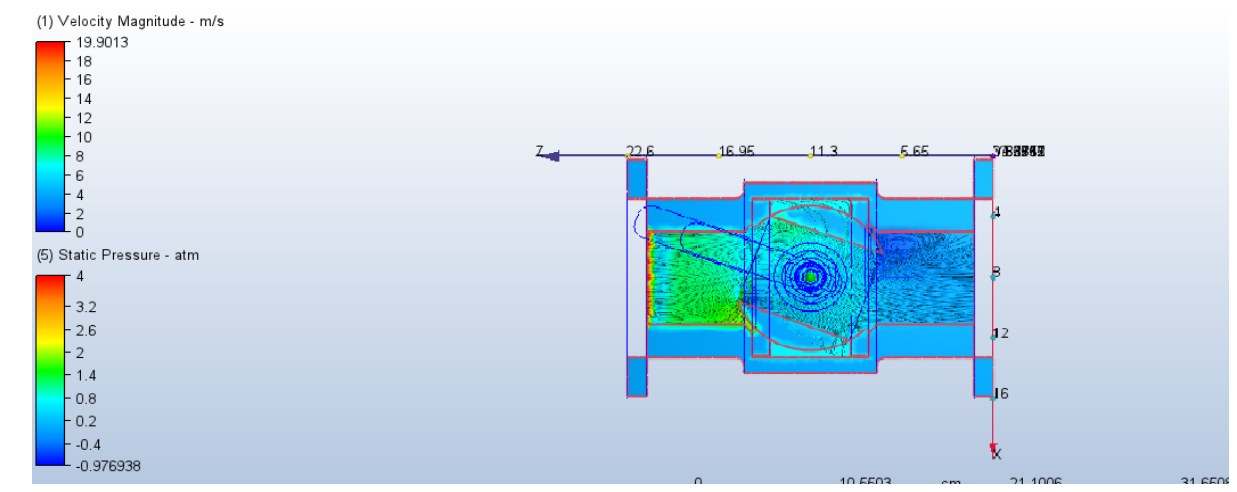

Gambar 3.5 Contour distribusi tekanan pada presentase bukaan valve 50\% tekanan $5 \mathrm{~atm}$ dan bukaan valve $70 \%$ tekanan $4 \mathrm{~atm}$

Berdasarkan countor distribusi pada masing masing bukaan valve dan tekanan yang berbeda dapat disimpulkan bahwa semakin besar bukaan valve maka semakin kecil pressure drop yang dihasilkan. Sebaliknya semakin kecil bukaan valve maka pressure drop yang dihasilkan semakin besar.

Pressure drop tersebut ditandai dengan perubahan warna dari kuning ke biru muda. Faktor yang menentukan laminar atau turbulennya suatu aliran adalah fluida, kecepatan bentuk dan ukuran benda yang berada di dalam aliran kedalaman air, bilangan Reynolds sendiri dipengaruhi oleh kecepatan aliran fluida air, semakin besar bilangan Reynolds maka semakin tinggi kecepatan aliran air sehingga akan membuat pressure drop meningkat. Pada countor distribusi bukaan valve terlihat bahwa aliran yang dihasilkan adalah aliran turbulensi.

Dari hasil penelitian dan pembahasan diatas dapat disimpulkan bahwa pengaruh bukaan valve dan tekanan terhadap pressure drop yaitu semakin tinggi tekanan masuk yang diberikan maka pressure drop yang dihasilkan semakin besar , hal ini dikarenakan besarnya tekanan yang hilang yang disebabkan karena fluida yang keluar dengan bukaan valve yang sama lebih besar dari pada tekanan masuk yang lebih kecil dan semakin kecil bukaan valve yang diberikan maka pressure dropnya akan semakin besar begitu juga untuk bilangan Reynold yang dihasilkan berbanding lurus dimana seakin besar bukaan valve dan tekanan yang diberikan, maka bilangan Reynoldnya akan semakin tinggi pula, hal ini terjadi karena 
peningkatan debit aliran yang disebabkan karena pengaruh besaran bukaan valve dan tekanan sehingga kecepatan alirannya semakin tinggi.

\section{Simpulan dan Saran}

Simulasi kavitasi dengan kavitasi bukaan valve 50\%, 55.86\%, 70\%, $84.14 \%$, dan 90\% memberikan gambaran bahwa kavitasi berpotensi terjadi pada presentasi bukaan yang lebih kecil dengan tekanan awal yang kecil, ini terjadi karena besarnya pressure drop yang terjadi yang melebihi tekanan uapnya.

Penelitian ini dapat dikembangkan dengan lebih lanjut dari penelitian ini adalah melakukan percobaan menggunakan model control valve dengan tipe lainnya dan melakukan penggambaran geometri valve sesuai aslinya. Kemudian penelitian ini dilanjutkan dengan mengganti laju alir dan jenis fluidanya sebagai variabel terikat.

\section{Daftar Pustaka}

1. Agustiyan, D. A., \& Dr Bambang Lelono Widjiantoro ST, M. (2007). Simulasi Kavitasi Pada Control Valve. 1-9. Surabaya. Institut Teknologi Sepiluh Nopember.

2. Celik, H. K., Rennie, A. E. W., Karayel, D., \& Akinci, I. (2011). Determination of Flow Parameters through CFD Analysis for Agricultural Irrigation Equipment: A Case Study for a Mini Valve. Tarım Makinaları Bilimi Dergisi, 7(3), 231-239.

3. A. Tabrizi, M. Asadi, G. Xie, G. Lorenzini and C. Biserni. (2014). Computational of Cavitation, Journal of Engineering Thermophysics Vol. 23 No.1, pp.

4. Flowserve. (2006). Flowserve Cavitation Control (pp. 1-20).

5. Hasbi, M. (2009). Pola Aliran Pada Downstream Katup. 1(1), 9-16

6. Muhtadi, M., L, B. D., Widjiantoro, S. M., Cordova, Hendra, S. M. (N.D). (2017). Analisis Reduksi Intensitas Kavitasi Pada Kontrol Valve Akibat Pressure Drop Dengan Metode Pressure Recovery Factor di Vaco Indonesia, 1-7. Surabaya. ITS. 
Sindi Qistina Asriani / Chemical Engineering Journal Storage $1: 2$ (Oktober 2021) 46-55

7. Shirazi, T. N., G. Reza Azizyam and G. Hossein Akbari. (2012). CFD Analysis Of the Ball Valve Performance In Presence Of Cavitation. Life Sci J. www.Lifesciencesite.com.

8. Syamsi Firdaus. (2017). Analisis Performa Modifikasi Propeller Ka-70 Menjadi Hubless Rim Driven Propeller. 1-108. Surabaya: Institut Teknologi Sepuluh November. 